\title{
A study on film score applying the Neo-Riemannian theory: focusing on Bernard Herrmann's mysterious island
}

\author{
Johee Lee* \\ Inho Lee* \\ *Corresponding author, Department of Performance Music, Graduate School of Hallyu Culture, \\ Kyonggi University, 1410, Geumhwagwan, 24, Kyonggidae-ro 9-gil, Seodaemun-gu 03746, \\ Republic of Korea, http://orcid.org/0000-0001-5652-8355, e-Mail: joheelee@naver.com \\ **First author, Department of Practical Music, Kyonggi University, 2307, Chungjeonggwan, 24, \\ Kyonggidae-ro 9-gil, Seodaemun-gu 03746, Republic of Korea, http://orcid.org/0000-0001- \\ 7096-0670, e-Mail: soulinno@kgu.ac.kr
}

DOI 10.12975/rastmd.2021933 Submitted November 3, 2021 Accepted December 19, 2021

\begin{abstract}
This paper, takes three pieces of music in the film score work Mysterious Island by film music composer Bernard Herrmann (1911-1975) as the analysis object. Bernard Herrmann's composition techniques are very innovative, and even difficult to interpret harmonic design when analyzing his works with tonal music. The Neo-Riemannian theory formed in the 1980s is used to analyze the chord progression that cannot be accurately explained by tonal music analysis in Bernard Herrmann's film score, and to prove the Neo-Riemannian theory by marking the transformation methods used and deriving the evolution process of harmony Neo-Riemannian theory's rationality and superiority in analyzing film music. This study hopes to use the Neo-Riemannian theory to provide a new perspective for exploring the development of film musicology.
\end{abstract}

Keywords

Neo-Riemannian theory, Transformational Theory, Bernard Herrmann, Film Score, Mysterious Island

\section{Introduction}

Film music from the beginning of the sound film era of Western romanticism "Leitmotif", to the "Theme" composition method, Ethnic Scales, Modal Harmony, Atonality and many other composition methods, all show the diversity and integration of film music. "Film musicology is a scholarly sub-discipline hardly twenty years old, and virtually no dedicated or sustained analytical attention was given to film scores in the conventional venues of Anglo-American music theoryjournals, conferences, monographs, and seminars-until a trickle began at the fin de millénnaire." ${ }^{1}$ The researcher also found that the theoretical analysis of film music has remained at the level of Functional Harmony based analysis after reviewing the Asian academic literature. This study argues that film music has developed into a completely independent musical composition system after the development of nearly a century. Therefore, when it comes to film music analysis, the traditional Tonal Music theory can no longer provide much theoretical basis for film music analysis.

1 Frank Martin Lehman, "Reading Tonality Through Film: Transformational Hermeneutics and the Music of Hollywood," (Ph.D. Diss., Harvard University, 2012), 1. 
For various musical analyses, Nicholas Cook, listed Traditional methods of analysis, Schenkerian analysis ${ }^{2}$, Psychological approaches to analysis, Formal approaches to analysis, and Techniques of comparative analysis. Among them, Formal approaches to analysis include set-theoretical analysis and semiotic analysis. The book provides a detailed introduction to various musical analysis and samples of analysis of music. "In the twentieth century, after Schenker's theory of hierarchical tonality (1935) and set theory as applied to atonal music most noticeably by Allen Forte (1973), transformational theory is the third important and far-reaching branch of structure-centered Englishlanguage music theory." 3

Neo-Riemannian theory is a theory of music analysis that emerged in the United States in the 1980s, based on the Transformational Theory proposed by David Lewin (1933-2003). In the early days, the theory was an interpretative analysis of the Chromatic Harmony of classical music composers such as Richard Wagner (1813-1883). "Neo-Riemannian theory arose in response to analytical problems posed by chromatic music that is triadic but not altogether tonally unified." 4 Richard Cohn summarized six concepts of Neo-Riemannian theory in the preface to Journal of Music Theory, (Vol. 2, 1998), which are "triadic transformations, 2 The work of Schenker himself, of his pupils, such as Oswald Jonas and Ernst Oster, and of contemporary practitioners. such as Allen Forte and John Rothgeb. Nicholas Cook, A Guide to Musical Analysis (W. W. Norton \& Company, 1992), 27.

3 Scott Murphy, "Transformational Theory and the Analysis of Film Music," in The Oxford Handbook of Film Music Studies, ed. David Neumeyer (Oxford University Press, 2013), 476.

4 Richard Cohn, "Introduction to Neo-Riemannian Theory: A Survey and a Historical Perspective," Journal of Music Theory 42, No. 2, (1998): 167. common-tone maximization, voiceleading parsimony, mirror or "dual" inversion, enharmonic equivalence and the "Table of Tonal Relations"." 5 Triadic transformations are a central part of Neo-Riemannian theory, centered around the movement between major and minor triads. It is free from the constraints of tonal music and Functional Harmony, and emphasizes the way in which harmony constitutes the transformation between musical elements. Just as "Composer Irwin Bazelon wrote that "film music is impatient. It has a function to perform and must make its presence felt without procrastination" (1975, 51). The immediate juxtaposition of two major or minor triads can fit this bill well, particularly when the juxtaposition is atypical." 6 such atypical forms do not necessarily need to be composed with Functional Harmony. Generally, these nonfunctional chord progressions can make a reasonable analysis with NeoRiemannian theory.

The Neo-Riemannian theory consists of a complex system of bifurcation theories. They range from transformations between major and minor triads to transformations between augmented triads and seventh chord, as well as transformations between set class 6-20 hexatonic (Figure 1), and set class 8-28 Octatonic (Figure 2), etc., all of which have been studied in the literature. The Neo-Riemannian theory is constantly being researched and expanded. In this study, the Neo-Riemannian theory for film music analysis is organized as follows.

5 Richard Cohn, Journal of Music Theory 42, No. 2, (1998): 169.

6 Scott Murphy, The Oxford Handbook of Film Music Studies, 484. 


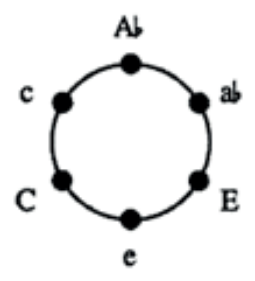

$\{0,3,4,7,8,11\}$

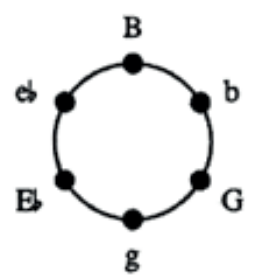

$\{2,3,6,7,10,11\}$

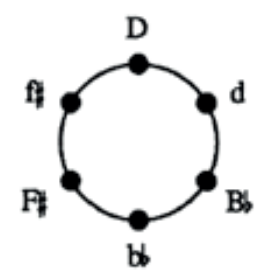

$\{1,2,5,6,9,10\}$

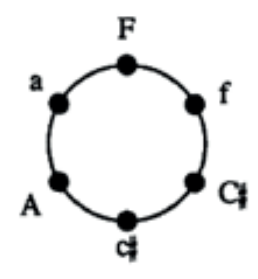

$[0,1,4,5,8,9]$

Figure 1. HexaCycles ${ }^{7}$

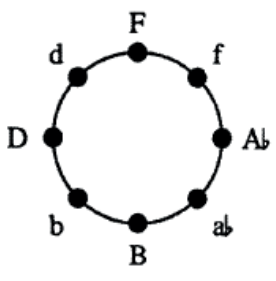

$\{0,2,3,5,6,8,9,11\}$

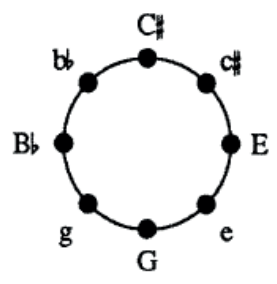

$\{1,2,4,5,7,8,10,11\}$

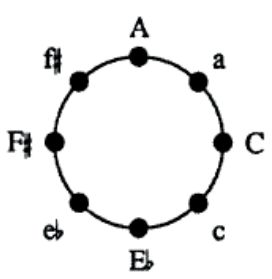

$\{0,1,3,4,6,7,9,10\}$

Figure 2. OctaCycles ${ }^{8}$

At first, David Lewin's Generalized Interval Systems $(\mathrm{GIS})^{9}$ proposed a more efficient theoretical system for analyzing Chromatic Harmony, which adapted the designation of Riemannian transformations in the theory to create three basic transformations of the theory of transformations: P, L, and $\mathrm{R}^{10}$. Richard Cohn extended the PLRGroup transformations based on David Lewin's $\mathrm{P}, \mathrm{L}$, and $\mathrm{R}$ transformations to derive three combined transformations:

7 HexaCycles constituted by hexatonic are derived from transformations theory. Jack Douthett and Peter Steinbach, "Parsimonious Graphs: A Study in Parsimony, Contextual Transformations, and Modes of Limited Transposition," Journal of Music Theory 42, No. 2, (1998): 245.

8 OctaCycles constituted by Octatonic are derived from transformations theory. Jack Douthett and Peter Steinbach, Journal of Music Theory 42, No. 2, (1998): 247.

9 David Lewin, Generalized Musical Intervals and Transformations, (Oxford University Press, 2007). 10 PAR: $\left(p^{\prime}\right.$ sign $)$ PAR $=\left(p^{\prime}\right.$ - sign $), \operatorname{REL}:\left(C^{\prime}+\right)$ REL $=(A$ ' -), LT: $\left(C^{\prime}+\right) \mathrm{LT}=(\mathrm{E}-)$. David Lewin, Generalized Musical Intervals and Transformations, (Oxford University Press, 2007), 178.
LP, PR, and LR. In particular, he created 4 different HexaCycles by LP transformations and 3 different OctaCycles by PR transformations, and hexatonic and Octatonic are often used in harmony and melodic compositions in science fiction films and thrillers. Richard Cohn also created $\mathrm{H}$ (Hexatonic Pole) ${ }^{11}$ transformations from LPL transformations, which were used in the analysis of the subject of this study. The types of transformations and methods of transformations used in this study are organized as follows (Table 1).

11 Richard Cohn, Audacious Euphony: Chromatic Harmony and the Triad's Second Nature, (Oxford University. Press, 2012), 31. 
Table 1. A summary of common transformations

\begin{tabular}{|c|c|c|}
\hline The names of transformations & The method of transformation & Ex. \\
\hline Tn (Transposition number) & Transpose by $n$ semitones & $\begin{array}{c}\mathrm{T} 1=\mathrm{C} \leftrightarrow \mathrm{C} \# \text { or } \\
\mathrm{T} 1=\mathrm{C} \leftrightarrow \mathrm{B}\end{array}$ \\
\hline $\begin{array}{c}\mathrm{P} \text { (arallel) } \\
\text { Is equivalent to } \\
\text { Riemannian transformations } \\
\mathrm{V} \text { (ariante) }\end{array}$ & $\begin{array}{l}\text { 1. root and fifth remain unchanged } \\
\text { 2. third semitone changes }\end{array}$ & $\mathrm{C} \leftrightarrow \mathrm{Cm}$ \\
\hline L(eittonwechsel) & $\begin{array}{l}\text { 1. root and fifth remain unchanged } \\
\text { 2. root semitone changes }\end{array}$ & $\mathrm{C} \leftrightarrow \mathrm{Em}$ \\
\hline $\begin{array}{c}\mathrm{R} \text { (elative) } \\
\text { Is equivalent to } \\
\text { Riemannian transformations } \\
\mathrm{P}(\text { arallel) }\end{array}$ & $\begin{array}{l}\text { 1. root and third remain unchanged } \\
\text { 2. fifth Whole-tone changes }\end{array}$ & $\mathrm{C} \leftrightarrow \mathrm{Am}$ \\
\hline LP & $L+P$ & $\begin{array}{c}\mathrm{C} \leftrightarrow(\mathrm{Em}) \leftrightarrow \mathrm{E} \leftrightarrow \\
(\mathrm{Abm}) \leftrightarrow \mathrm{A} b \leftrightarrow(\mathrm{Cm}) \leftrightarrow \mathrm{C}\end{array}$ \\
\hline PR & $\mathrm{P}+\mathrm{R}$ & $\begin{array}{c}\mathrm{C} \leftrightarrow(\mathrm{Cm}) \leftrightarrow \mathrm{Eb} \leftrightarrow \\
(\mathrm{Ebm}) \leftrightarrow \mathrm{F} \# \leftrightarrow(\mathrm{F \# m}) \\
\leftrightarrow \mathrm{A} \leftrightarrow(\mathrm{Am}) \leftrightarrow \mathrm{C}\end{array}$ \\
\hline LR & $L+R$ & $\begin{array}{c}\mathrm{C} \leftrightarrow \mathrm{G} \leftrightarrow \mathrm{D} \leftrightarrow \mathrm{A} \leftrightarrow \mathrm{E} \leftrightarrow \mathrm{B} \\
\leftrightarrow \mathrm{F} H \leftrightarrow \mathrm{Db} \leftrightarrow \mathrm{A} b \leftrightarrow \mathrm{Eb} \leftrightarrow \mathrm{Bb} \\
\leftrightarrow \mathrm{F} \leftrightarrow \mathrm{C}\end{array}$ \\
\hline H (Hexatonic Pole) & $L+P+L$ & $\mathrm{C} \leftrightarrow \mathrm{Abm}$ \\
\hline
\end{tabular}

Bernard Herrmann's film score works are selected for this study. At the peak of his composing period, when his contemporaries were still using the composing techniques of the romantic era to compose film scores, Bernard Herrmann had already formed his own style of Minimalist modular phrase structure. The chord progression gradually blurred tonal, the Texture and Orchestration also went away from the romantic era style, and a lot of nontraditional instruments were adopted.
In the early days, before Bernard Herrmann developed his own style, his compositional technique was based on that of Max Steiner (1888-1971). But it is also apparent that he excelled at string tension effects. Bernard Herrmann has deeply influenced contemporary Hollywood composers as a synonym of film score for thrillers, horror films, suspense films, science fiction films and other films. Composer Danny Elfman once paid tribute to Bernard Herrmann: 
I was a big Bernard Hermann fan as a kid, in the '60s. I guess what you'd call kind of like a film-music nerd. My training was spending every weekend at the movie theater-I didn't play sports, I didn't really go out in the sun-I hated being out in the sun. I loved being inside a theater; it suited me well, and I lived around the block from one. I love films and I loved film music. I knew that if Bernard Hermann did the music that it was going to be a great film. ${ }^{12}$
Mysterious Island is a science fiction adventure film released in 1961. Bernard Herrmann composed the music and conducted the London Symphony Orchestra (Figure 3). <Exploration>, $<$ The Volcano>, and <The Pipeline>, which are string works, were selected as the analysis subjects. They were analyzed by using Neo-Riemannian theory. The scores were created by the author by using the Sibelius software for Piano reduction.

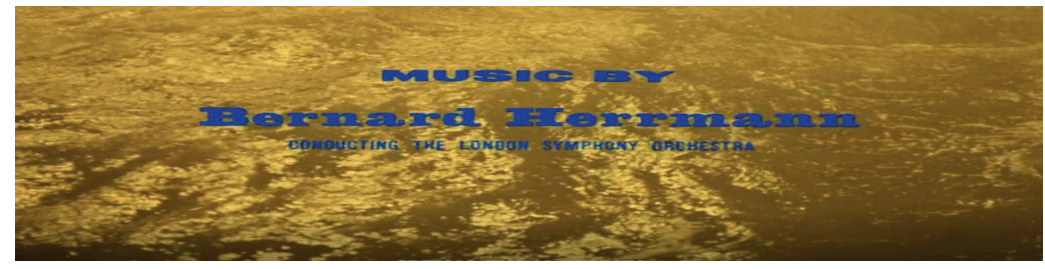

Figure 3. The opening scene

\section{Problem of Research}

Following the advancement of film music, certain chord progressions used in compositions have become difficult to analyse accurately through traditional tonal music system analysis. Using NeoRiemannian theory to analyse these harmonies in a rational way, this study systematically collates the results of this analysis, with the aim of clarifying the feasibility of Neo-Riemannian theory in analyzing these harmonies and bringing some new insights into the progress of film musicology.

\section{Research Method/ Method Research Model}

Research in the field of film music analysis has mostly focused on tonal music systems, and some of the results have been unsatisfactory. Having compared numerous methods of music analysis,

12 Richard Davis, Complete Guide to Film Scoring, (Berklee Press; 2nd edition, 2010), 278. the researcher in this study chose NeoRiemannian theory as the method of study. Since Neo-Riemannian theory was first developed as an analytical theory for the analysis of musical works from the Romantic period, and early film music was composed precisely from imitations of Romantic music, there was sufficient theoretical basis for choosing Neo-Riemannian theory as a research method.

\section{Data Collection Tool/Document}

This article chooses Mysterious Island as the object of analysis and data collection. In reviewing prior research, the researcher found that of the many analyses of composer Bernard Herrmann's works, not many academic studies have used Mysterious Island as an object of analysis. In addition, the music of this piece has features that make it impossible to analyse tonal music, hence making it an object of analysis. 


\section{Data Analysis}

Using <Exploration>, <The Volcano>, and <The Pipeline>, three pieces of music from the film Mysterious Island, as a harmonic analysis, this study presents the use of Neo-Riemannian theory in the analysis by identifying the harmonic transitions in Piano reduction and visualising the harmonic trajectory through Transformational network.

\section{Results}

It is concluded from this analysis that the subject of this study is unable to use the tonal music system to give a reasonable analysis, however, the analysis process through Neo-Riemannian theory can result in six transformations to explain chord progressions. The use of Neo-Riemannian theory is logical and superior for the analysis of chord progressions in film music.

\section{Analysis}

Mysterious Island is about the American

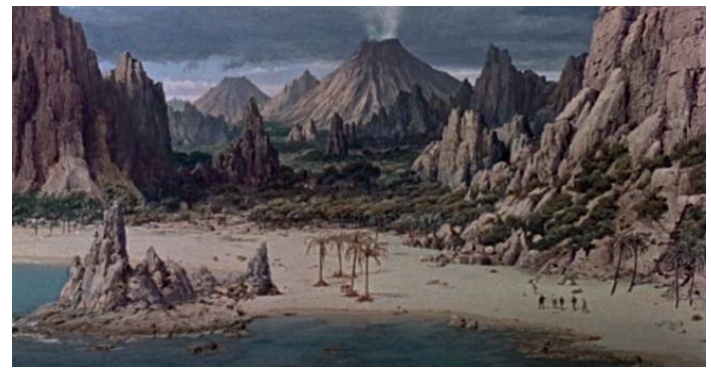

Civil War. Captives of Union Figurehters and prisoners of the Alliance ride in a hot air balloon and are trapped on an island in the South Pacific because they can't control the wind direction after landing. The island is home to huge plants and animals, as well as a mysterious underground base, and they need to escape mysterious island before the volcano on the island erupts.

1. <Exploration> harmony and music analysis

The clip of <Exploration> describes that the landscape of the island is a combination of strangeness and beauty. Tropical palm trees and sandy beaches surround <The Volcano>, spreading wonderful hues and strange colors everywhere, and the picture presents a mysterious and fantastical landscape (Figure 4).

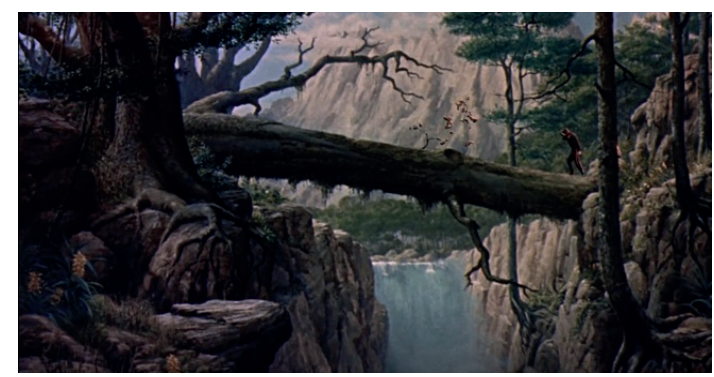

Figure 4. The clip of <Exploration>

The Piano reduction (Figure 5 ) shows that the scale consists of $C D b D E b E$ $F \# G A b A B b$ and $B$. The chord consists of $B$ minor $(B / D / F \#)$, $D$ minor $(D / F / A)$, and $\mathrm{B} b$ minor $\left(\mathrm{B}_{b} / \mathrm{D}_{\mathrm{b}} / \mathrm{F}\right)$ (Table 2). According to Tonal Music theory and Functional Harmony analysis, it is difficult to judge what kind of key the scale belongs to, and chord progression does not follow Functional Harmony. 


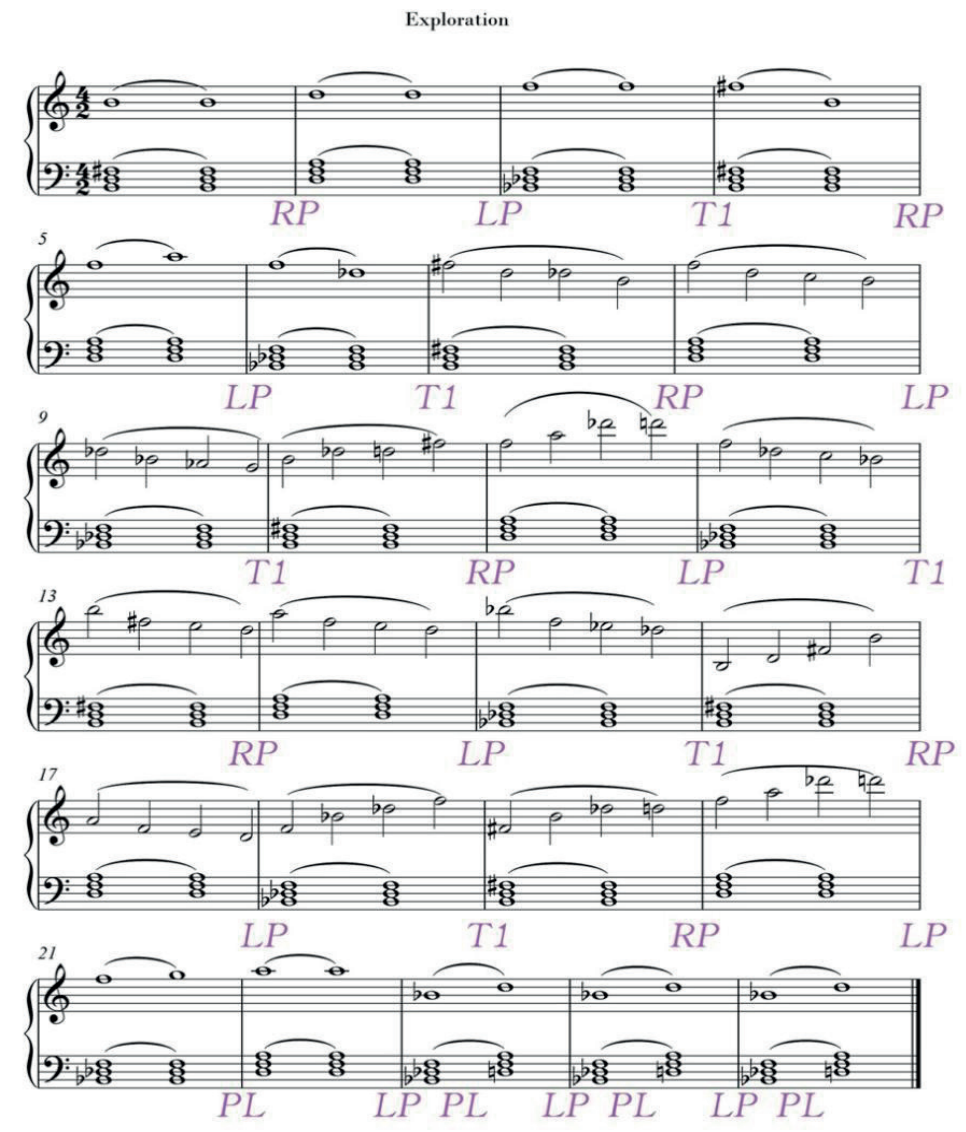

Figure 5. Piano reduction of <Exploration $>$

Table 2. < Exploration> chord

\begin{tabular}{|c|c|c|c|c|c|c|c|c|c|}
\hline Measure & 1 & 2 & 3 & 4 & 5 & 6 & 7 & 8 & 9 \\
\hline chord & $\mathrm{Bm}$ & $\mathrm{Dm}$ & $\mathrm{Bbm}$ & $\mathrm{Bm}$ & $\mathrm{Dm}$ & $\mathrm{Bbm}$ & $\mathrm{Bm}$ & $\mathrm{Dm}$ & $\mathrm{Bbm}$ \\
\hline Measure & 10 & 11 & 12 & 13 & 14 & 15 & 16 & 17 & 18 \\
\hline chord & $\mathrm{Bm}$ & $\mathrm{Dm}$ & $\mathrm{Bbm}$ & $\mathrm{Bm}$ & $\mathrm{Dm}$ & $\mathrm{Bbm}$ & $\mathrm{Bm}$ & $\mathrm{Dm}$ & $\mathrm{Bbm}$ \\
\hline Measure & 19 & 20 & 21 & 22 & 23 & 24 & 25 & & \\
\hline chord & $\mathrm{Bm}$ & $\mathrm{Dm}$ & $\mathrm{Bbm}$ & $\mathrm{Dm}$ & $\begin{array}{c}\mathrm{Bbm} \\
\mathrm{Dm}\end{array}$ & $\begin{array}{c}\mathrm{Bbm} \\
\mathrm{Dm}\end{array}$ & $\begin{array}{c}\mathrm{Bbm} \\
\mathrm{Dm}\end{array}$ & \\
\hline
\end{tabular}

Applying the principle of transformations The evolution of triads transformations of Neo-Riemannian theory and is that Bm uses RP transformations to putting aside the framework of Tonal generate $\mathrm{Dm}(\mathrm{Bm} \rightarrow \mathrm{R} \rightarrow \mathrm{D} \rightarrow \mathrm{P} \rightarrow \mathrm{Dm}), \mathrm{Dm}$ Music theory, one can analyze the uses LP transformations to generate transformations identified in Figure 6. $B\llcorner m \quad(D m \rightarrow L \rightarrow B b \rightarrow P \rightarrow B b m)$, $B b m$ uses 
$\mathrm{T} 1$ to generate $\mathrm{Bm} \quad(\mathrm{B} b \mathrm{~m} \rightarrow \mathrm{T} 1 \rightarrow \mathrm{Bm})$, and $\mathrm{B} b \mathrm{~m}$ uses $\mathrm{PL}$ transformations to generate $\mathrm{Dm} \quad\left(\mathrm{B} b \mathrm{~m} \rightarrow \mathrm{P} \rightarrow \mathrm{B}_{b} \rightarrow \mathrm{L} \rightarrow \mathrm{Dm}\right)$. The chord progression of the soundtrack can be observed more intuitively through the Transformational network ${ }^{13}$ (Figure 6), and the harmony effect presented by the RP - LP - T1 - RP - LP - PL transformations demonstrates that such chord progression greatly blurs tonal, showing the unpredictability and non-termination of chord progression. The harmony effect produced is in line with the mysterious and fantastical atmosphere presented by the film. String music and a harp are used, and the tone enhances the fantastical atmosphere. Bernard Herrmann's score is not only musically advanced, but also highly acoustic.

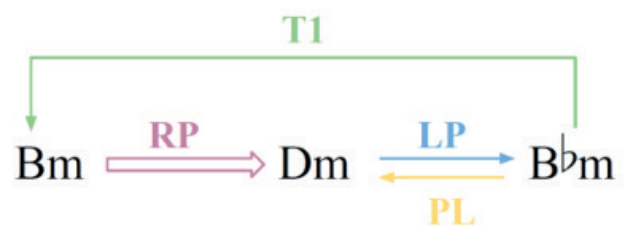

Figure 6. Transformational network of <Exploration>

2. <The Volcano> harmony and music analysis

The clip of <The Volcano> is about a volcanic crater on mysterious island with a lot of smoke (Figure 7). A group of five people climb the volcano to go check it out.

13 This method can be used for a simple and intuitive observation of transformations. Frank Lehman, "Film Music and Neo-Riemannian Theory", Oxford Handbooks Online: Aug 2014, https://www.oxfordhandbooks.com/view/10.1093/ oxfordhb/9780199935321.001.0001/oxfordhb9780199935321-e-002 (accessed Sep 15, 2021). 
The Volcano
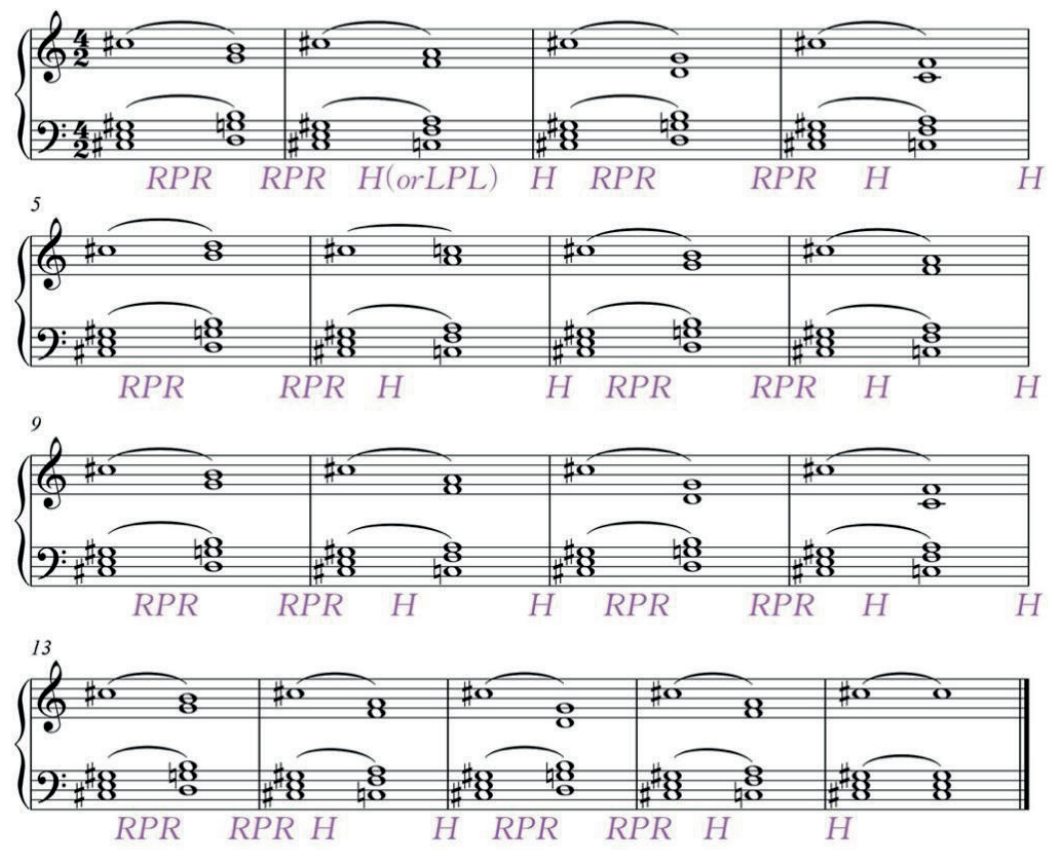

Figure 8. Piano reduction of <The Volcano>

Table 3. < The Volcano> chord

\begin{tabular}{|c|c|c|c|c|c|c|c|c|c|}
\hline Measure & 1 & 2 & 3 & 4 & 5 & 6 & 7 & 8 & 9 \\
\hline chord & $\begin{array}{c}\mathrm{C} \# \mathrm{~m} \\
\mathrm{G}\end{array}$ & $\begin{array}{c}\mathrm{C} \# \mathrm{~m} \\
\mathrm{~F}\end{array}$ & $\begin{array}{c}\mathrm{C} \# \mathrm{~m} \\
\mathrm{G}\end{array}$ & $\begin{array}{c}\mathrm{C} \# \mathrm{~m} \\
\mathrm{~F}\end{array}$ & $\begin{array}{c}\mathrm{C} \# \mathrm{~m} \\
\mathrm{G}\end{array}$ & $\begin{array}{c}\mathrm{CHm} \\
\mathrm{F}\end{array}$ & $\begin{array}{c}\mathrm{CHm} \\
\mathrm{G}\end{array}$ & $\begin{array}{c}\mathrm{C} \# \mathrm{~m} \\
\mathrm{~F}\end{array}$ & $\begin{array}{c}\mathrm{C} \# \mathrm{~m} \\
\mathrm{G}\end{array}$ \\
\hline Measure & 10 & 11 & 12 & 13 & 14 & 15 & 16 & 17 & \\
\hline chord & $\begin{array}{c}\mathrm{C} \# \mathrm{~m} \\
\mathrm{~F}\end{array}$ & $\begin{array}{c}\mathrm{C} \# \mathrm{~m} \\
\mathrm{G}\end{array}$ & $\begin{array}{c}\mathrm{C} \# \mathrm{~m} \\
\mathrm{~F}\end{array}$ & $\begin{array}{c}\mathrm{C} \# \mathrm{~m} \\
\mathrm{G}\end{array}$ & $\begin{array}{c}\mathrm{C} \# \mathrm{~m} \\
\mathrm{~F}\end{array}$ & $\begin{array}{c}\mathrm{C} \# \mathrm{~m} \\
\mathrm{G}\end{array}$ & $\begin{array}{c}\mathrm{CH} \mathrm{m} \\
\mathrm{F}\end{array}$ & $\mathrm{CHm}$ & \\
\hline
\end{tabular}

By observing the melody in Figure 8 , we can see that the first two beats of each measure are $C \#$, while the next two beats of mm.1 - 4 and mm.9-12 are B - A - G - F, and mm.5 - 8 are D - C - B - A. This sequential downward phrase structure shows that the composer made a top-down melody to echo the picture of climbing from the bottom to the top. The transformations in Figure 8 use both RPR and $\mathrm{H}$ transformations corresponding to the $\mathrm{C} \# \mathrm{~m}-\mathrm{G}$ and $\mathrm{C} \# \mathrm{~m}$ - $\mathrm{F}$ chord progressions. The evolution of the triads transformations is that $\mathrm{C} \# \mathrm{~m}$ uses RPR transformations to generate $G$ $(C \forall m \rightarrow R \rightarrow E \rightarrow P \rightarrow E m \rightarrow R \rightarrow G)$, and $C \# m$ uses $\mathrm{H}$ transformations to generate $\mathrm{F}$ $(C \exists m \rightarrow L \rightarrow A \rightarrow P \rightarrow A m \rightarrow L \rightarrow F)$. The sound effect produced gives a sense of tension and curiosity about the unknown, and this chord progression and Minimalist modular phrase structure is Bernard Herrmann's preferred technique of creation. The Transformational network also shows the path of chord progression transformation in a simple and clear way (Figure 9). 


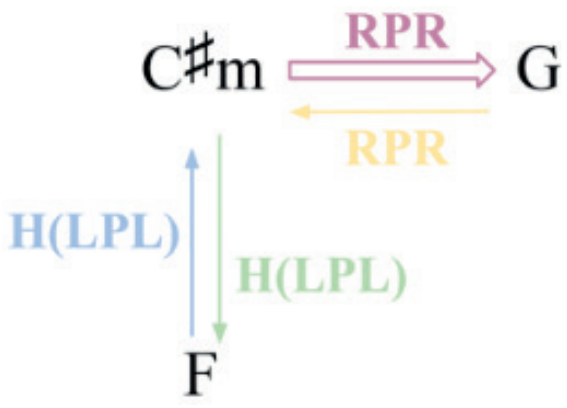

Figure 9. Transformational network of $<$ The Volcano>

3. <The Pipeline> harmony and music analysis

The clip of <The Pipeline> narrates that with the help of the Lord of mysterious island, they work together to use the trees on the island (Figure 10) to make a pipe to convey air pressure to help the sunken ship float to escape mysterious island before the volcanic eruption.

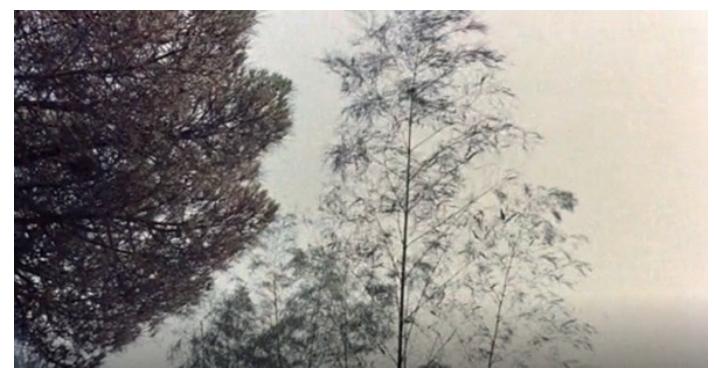

Figure 10. The clip of <The Pipeline>

Through Piano reduction (Figure 11), it is concluded that the scale is composed of $C D_{b} D E F F \# G A b A B b$ and B. Most of the melody is performed in the pattern of upward or downward Phrase of Half note. A comparison between Figure 11 and Figure 5 reveals that the composition of the melody is same except for $\mathrm{mm} .13$ and $\mathrm{mm} .16$, the rest of the measure can be matched to the same melody in the clip of <Exploration> (mm.3 and the reverse of $\mathrm{mm} .12$ in the clip of <Exploration>). As if Bernard Herrmann could create countless new music by moving the modular structure around in the music, which also provides more possibilities for the creation of melodies.

Frank Lehman, a film music analyst, stated in his article on the harmony and melody of Mysterious Island that:

Despite the fact that Herrmann's passage is clearly not a random assemblage of pitches, the tendency in film musicology with regard to passages such this-which are extremely common and characteristic of scores for "genre"-has been to fall back on analytical nonexplanations. Abundant and audience-understood progressions are cause for the invoking of "nonfunctional" harmonies, "constant modulation," "polytonality," and "unrelated keys/ chords."14

His composing technique is a bold break with traditional compositional methods, and establishes a highly personal and innovative compositional technique. Chord progression (Table 4) is identical to the clip of <Exploration>, using the same RP transformations, LP transformations, T1 transformations, and PL transformations. So it can be assumed that Bernard Herrmann uses the same chord progression to suggest that the characters are about to leave mysterious island. It echoes the atmosphere described in the clip of

14 Frank Lehman, "Film Music and Neo-Riemannian Theory", Oxford Handbooks Online (accessed Sep 15, 2021). 
$<$ Exploration> just after landing on the the film. And compared to the clip of island, giving the audience a hint of <Exploration>, Low voice of Woodwind the fantasy atmosphere of mysterious instruments is added, and the overall island through music for the last time. music is a bit more mysterious and At the same time, this clip is the final serious. emergence of strings as the melody of

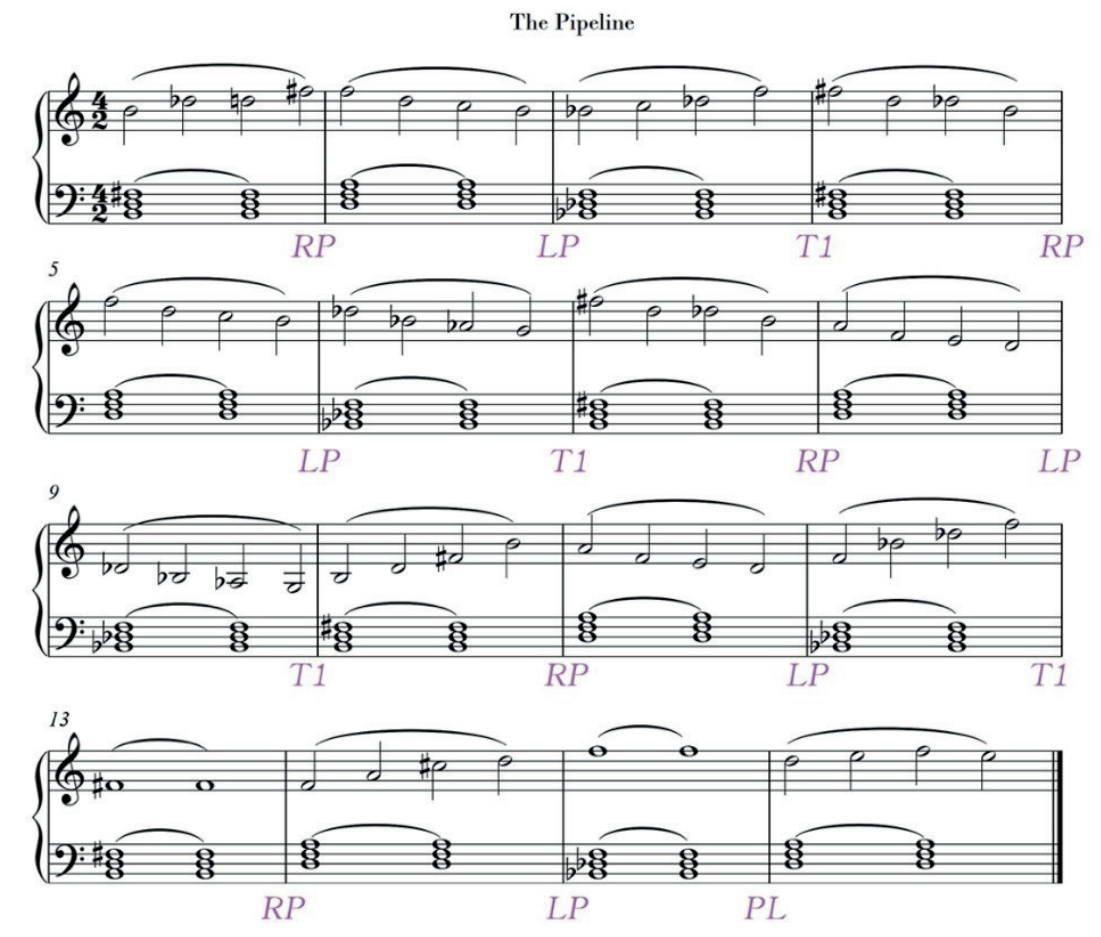

Figure 11. Piano reduction of <The Pipeline>

Table 4. <The Pipeline> chord

\begin{tabular}{|c|c|c|c|c|c|c|c|c|}
\hline Measure & 1 & 2 & 3 & 4 & 5 & 6 & 7 & 8 \\
\hline chord & $\mathrm{Bm}$ & $\mathrm{Dm}$ & $\mathrm{Bbm}$ & $\mathrm{Bm}$ & $\mathrm{Dm}$ & $\mathrm{Bbm}$ & $\mathrm{Bm}$ & $\mathrm{Dm}$ \\
\hline Measure & 9 & 10 & 11 & 12 & 13 & 14 & 15 & 16 \\
\hline chord & $\mathrm{Bbm}$ & $\mathrm{Bm}$ & $\mathrm{Dm}$ & $\mathrm{Bbm}$ & $\mathrm{Bm}$ & $\mathrm{Dm}$ & $\mathrm{Bbm}$ & $\mathrm{Dm}$ \\
\hline
\end{tabular}




\section{Conclusions and Recommendations}

This study investigates the harmony and musical characteristics of Bernard Herrmann's film scores, and gives a reasonable basis for the analysis of chord progressions that cannot be accurately explained by using Tonal Music theory. The analysis of the three works summarizes that the chord progressions use RP transformations, LP transformations, PL transformations, RPR transformations, $\mathrm{H}$ transformations, and T1 transformations. These transformations can create a mysterious and fantastical harmony, and the Orchestration Minimalist modular phrase structure and unique instrumentation also help the soundtrack promote the progress of the story.

Although there was no Neo-Riemannian theory in Bernard Herrmann's time, and he never thought that in the future, researchers would use a new theory to analyze his own works. But research has revealed that Bernard Herrmann's composing techniques were advanced. His chord progressions are unpredictable and non-terminating in nature. His scores have defined Hollywood film music styles such as thriller, horror films, suspense films, and science fiction films, and have influenced contemporary composers.

\section{Recommendations for Further}

\section{Research}

This study concludes that the NeoRiemannian theory is a powerful tool for music analysis and can provide more possibilities for the development of film musicology. It also hopes that scholars will keep promoting and expanding the application of the Neo-Riemannian theory in the analysis of various film music styles.

\section{Limitations of Study}

There may be some possible limitations in this study. Due to the relatively deficit of music repertoires and chord progressions, there are no sufficient chord progressions to reflect in detail of the transformations in Neo-Riemannian theory, so it is impossible to fully demonstrate Neo-Riemannian theory in analyzing the comprehensiveness of film music. These limitations in this study that could be addressed in future research. The study focused on choosing more different styles of film music for transformations analysis, in order to demonstrate the rationality and comprehensiveness of the NeoRiemannian theory as a film music analysis tool. 


\section{Biodata of Authors}

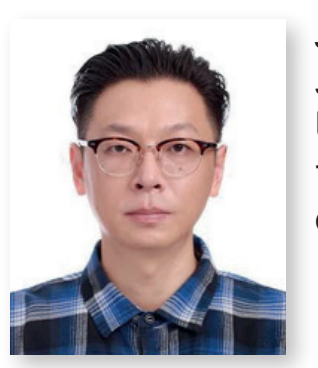

\section{Johee Lee}

Johee Lee is an assistant professor of performance music at Kyonggi University. His research covers a variety of analysis in composition, including film music and computer music. He received his master's degree and $\mathrm{PhD}$ from Kyonggi University.

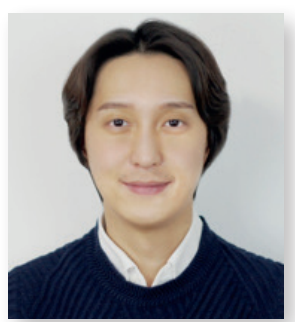

Inho Lee

Inho Lee is an assistant professor of practical music at Kyonggi University. His research covers a variety of musical themes, including Korean pop music and music education. He received his master's degree and PhD from Kyung Hee University and has worked as a vocal trainer for many K-pop artists. 


\section{References}

Cohn, Richard. Audacious Euphony: Chromatic Harmony and the Triad's Second Nature. Oxford University Press, 2012.

Cohn, Richard. "Introduction to NeoRiemannian Theory: A Survey and a Historical Perspective." Journal of Music Theory 42, No. 2, (1998): 167-169.

Cook, Nicholas. A Guide to Musical Analysis. W. W. Norton \& Company, 1992.

Cornelius, Steven. Natvig, Mary. Music: A Social Experience. Routledge; 2 edition, 2018.

Davis, Richard. Complete Guide to Film Scoring. Berklee Press; 2nd edition, 2010.

Douthett, Jack(Editor). Hyde, Martha M(Editor). Smith, Charles J(Editor). Music Theory and Mathematics: Chords, Collections, and Transformations. University of Rochester Press, 2008.

Douthett, Jack and Steinbach, Peter. "Parsimonious Graphs: A Study in Parsimony, Contextual Transformations, and Modes of Limited Transposition." Journal of Music Theory 42, No. 2, (1998): 245-247.

Gollin, Edward(Editor). Rehding, Alexander(Editor). The Oxford Handbook of Neo-Riemannian Music Theories. Oxford University Press, 2014.

Herrmann, Bernard. Mysterious Island. Directed by Cy Endfield. Los Angeles: Columbia, 1961.
Lewin, David. Generalized Musical Intervals and Transformations. Oxford University Press, 2007.

Lehman, Frank Martin. "Reading Tonality Through Film: Transformational Hermeneutics and the Music of Hollywood." Ph.D. Diss., Harvard University, $2012: 1$.

Lehman, Frank. "Film Music and NeoRiemannian Theory". Oxford Handbooks Online: Aug 2014. https://www. oxfordhandbooks.com/view/10.1093/ oxfordhb/9780199935321.001.0001/ oxfordhb-9780199935321-e-002 (accessed Sep 15, 2021).

Murphy, Scott. "Transformational Theory and the Analysis of Film Music," in The Oxford Handbook of Film Music Studies, ed. David Neumeyer. Oxford University Press, 2013.

Rehding, Alexander. Hugo Riemann and the Birth of Modern Musical Thought. Cambridge University Press, 2003.

Rings, Steven. Tonality and Transformation. Oxford University Press, 2011.

Schneider, Steven Jay. 1001 Movies You Must See Before You Die. B.E.S, 2019.

Schwarz, David Bard. Cohn, Richard. David Lewin's Morgengruß: Text, Context, Commentary. Oxford University Press, 2015. 